\title{
Barriers to hospital births: why do many Bolivian women give birth at home?
}

\author{
Kelsey E. Otis ${ }^{1}$ and John A. Brett ${ }^{2}$
}

Suggested citation

Otis KE, Brett JA. Barriers to hospital births: why do many Bolivian women give birth at home? Rev Panam Salud Publica. 2008;24(1):46-53.

\begin{abstract}
Objectives. This study investigated the low rates of hospital/health center births recorded in Yapacani, Bolivia, that persist despite the national maternal-infant insurance program designed to ensure equitable access to free center-based health care services for pregnant women. The purpose of this study was to identify the multilevel factors inhibiting access to and utilization of public health centers for labor and delivery.

Methods. Qualitative research methods were used, including participant observation, semistructured interviews of 62 community members, and key informant interviews with eight regional experts. Data were coded and analyzed using the grounded theory approach.

Results. From the semistructured interview data, five reasons for the low rate of institutional births and their frequency were identified: (1) fear or embarrassment related to receiving care at a public health care center (37\%); (2) poor quality of care available at the health care centers (22\%); (3) distance from or other geographic issues preventing timely travel to health care services (21\%); (4) economic constraints preventing travel to or utilization of health care services (14\%); and (5) the perception that health care services are not necessary due to the experience of "easy birth" (6\%).

Conclusions. The reasons for the low rate of births in public health centers exist within the context of deficient resources, politics, and cultural differences that all influence the experience of women and their partners at the time of birth. These large scale, contextual issues must be taken into account to improve access to quality health care services for all Bolivian women at the time of birth. Resources at the national level must be carefully targeted to ensure that governmental services will successfully instill confidence in Bolivian women and facilitate their overcoming the cultural, geographic, economic, and logistical barriers to accessing "free" services.
\end{abstract}

Key words Home childbirths; birth centers, hospital; humanizing child birth; health policy; maternal mortality; Bolivia.

More than half a million women, the majority of whom live in poor countries,

Department of Anthropology, University of Colorado, Denver, Colorado, United States of America. Send correspondence to Kelsey Otis, Ibis Reproductive Health, 17 Dunster Street, Suite 201, Cambridge, MA 02138, USA; telephone: +01-617349-0024; fax: 617-349-0041; e-mail: kotis@ibis reproductivehealth.org.

2 Department of Anthropology, University of Colorado Denver, Denver, Colorado, United States of America. die each year due to pregnancy-related complications (1). The disparities in mortality ratios between developed and developing countries reported by the United Nations (2) underscore the largely preventable nature of these deaths and the importance of access to a medical setting where pregnancy and birth complications can be managed. Bolivia's overall maternal mortality ratio of 420 per 100000 live births is extremely high in comparison with other countries in Latin America (2). The rate of institutional births often serves as a proxy for mortality risk (3-12). Medical care received for labor and delivery in a health facility can have several advantages over giving birth at home, including hygienic conditions and the ability to identify relevant risk factors and manage complications, especially when facilities are well-equipped and properly staffed. However, this is not necessarily a good 
proxy given the sometimes low quality of biomedical reproductive care in government health facilities. Thus, in order to understand pregnancy-related risk in countries with high maternal mortality, it is important to go beyond correlation of medical facility utilization with risk, and to examine the various factors involved in the low rate of institutional births, plus the quality of the care these facilities offer. The purpose of this study was to identify the multilevel factors inhibiting access to and utilization of public health care services for labor and delivery in Bolivia.

This study was based in Yapacaní, an impoverished rural lowland municipality located in the department of Santa Cruz, Bolivia. The majority of families in Yapacaní are immigrant agriculturists from the impoverished highlands. At the time of this research (2005), 71\% of the residents of Yapacaní were living below the poverty level (13) and only primary health care centers with general doctors and minimally-trained health workers were available. The primary care hospital in Yapacaní's urban center is very small relative to the population, and therefore, is often overcrowded. The many rural communities in Yapacaní are reached by bumpy dirt roads that are impassable after rainfall and have only basic infrastructure, i.e., a school, a soccer field, and in some cases, a small store and/or community-level health center. Bolivia's maternal health disparities are obvious in Yapacaní. According to the United Nations Development Program (14), $19.8 \%$ of women in the poorest quintile of the Bolivian population are attended to by a skilled health care professional versus $97.9 \%$ of women in the richest quintile. Maternal mortality ratios have been estimated to be 274 per 100000 live births in urban areas versus 524 in rural areas like Yapacaní (15).

Despite the various iterations of maternal-child health programs in Bolivia, beginning with the Seguro Nacional de Maternidad y Niñez (SNMN) in 1996, followed by the Seguro Básico de Salud (SBS) in 1998, and then the universal insurance plan Seguro Universal MaternoInfantil (SUMI) in 2002, disparities in maternal mortality risk persist. All three programs have been based on international health policy and have sought to reduce maternal-child mortality by improving access to quality health care ser- vices for women in the prenatal stage through 6 months postpartum and for children from newborn to 5 years of age (16). Success, however, has not been achieved, as shown by the low utilization rates of SUMI birthing services. This is especially true in rural and/or poor areas. In Yapacaní, $80 \%$ of pregnant women accessed prenatal services through SUMI in 2004, but according to hospital records, only $37 \%$ gave birth in a hospital or community-level health center. The remaining $63 \%$ either paid for private services, delivered at home, or traveled a significant distance to health services in another municipality. That the majority of women in Yapacaní access free prenatal care, but not the birthing services provided by SUMI, demonstrates the complexity of health care delivery. Given the relatively high risk of birth-related complications, it is important to understand the Bolivian health care system's failure to attract women to free birthing services.

In addition to SUMI, current reforms in Bolivia's health care system (mandated by the Popular Participation Law (Ley de Participación Popular, LPP) of 1994) include decentralizing management, resources, quality control, and evaluation to the local sector (16). While the law seeks to reduce the inefficiencies of a centrallybased system by encouraging the public participation in all aspects of the government, the system continues to be a fundamentally vertical one, with the national Ministry of Health and Sports (Ministerio de Salud y Deportes, MSD) in La Paz having ultimate control over key resources (e.g., health workers' salaries) and administration. The MSD recognizes that the success of these health care reforms has been limited to a few establishments and that true transformation is challenging (16). Evaluations of SNMN and SBS by the Pan American Health Organization concluded that services had not reached the poorest population groups; were not publicized or well-known, especially in rural areas; that municipal governments had been very slow to pay for services; that the availability of medical supplies was a problem; and that there were disparities in the use of municipal funds (17). Understanding the reasons for these failures and evaluating the ability of SUMI to overcome the challenges is important for Bolivian public health officials charged with reducing ma- ternal morality rates through equitable access to quality reproductive health care.

Because this study focused on the local stakeholders' need to understand why women were not accessing the health clinics for childbirth, data were not collected for cases where women did access these facilities. The results of this study have been used by the Centro de Promoción Agropecuaria Campesina (CEPAC)-a grassroots nongovernmental organization working to improve health care in rural municipalities-and Bolivian policy makers seeking to address the lack of access and/or use of SUMI-provided health care services.

\section{MATERIALS AND METHODS}

This research is structured through a socioecological framework that views health as the result of a complex set of interactions among ecological, biological, and sociocultural factors (18-20). From this perspective, maternal mortality is understood to take place within specific social, cultural, geographic, and political contexts, and is not simply the result of proximal medical factors, such as hemorrhage, infection, or obstructed labor. It also highlights the effects of global politicaleconomic forces and poverty on maternal health. By revealing the intersecting influences on pregnancy-related mortality, the successes and failures that SUMI has experienced in the face of alarming maternal mortality ratios and internal health disparities can be more fully understood.

This study utilized qualitative methods to better understand the perspective of pregnant women and their partners regarding governmental reproductive health services in Yapacaní. The research was conducted in 2005 at the request of and in collaboration with CEPAC. Qualitative methods allow for local-level explanatory research, without the constraint of predetermined analytical categories, and produce detailed, people-oriented understandings of health-related issues (21). Where many previous studies of the factors influencing institutional birth rates have used multivariate statistics to correlate socioeconomic and demographic characteristics with birth setting $(3,7,11$, 22-24), qualitative methods allow for a deeper, more personal understanding of 
the numerous, intertwined factors at work between international health policy and its implementation and the experiences of women accessing health care. Qualitative methods elicit individual factors (e.g., income or ethnicity), but also contextual and macrolevel factors influencing women's health care decisions and outcomes.

Data were derived from four methods: participant observation, semistructured interviews, open-ended interviews, and analysis of written documents. Participant observation refers to attendance at the weekly, administrative meetings of the municipal health service and CEPAC over the course of two months, and nonmedical observation of daily routines at the health centers and the hospital in Yapacaní where SUMI services are offered (once per week for two months). These observations created a detailed understanding of daily routines, beliefs, and relationships within the health care system and provided context to the themes emerging from interviews.

Semistructured interviews were conducted with 44 mothers and 18 fathers of children under 5 years of age. Interviews were conducted with fathers in order to obtain a more comprehensive picture of how medical decisions were being made in the household. Half of the interviewees were mothers and fathers whose child had been born at a government health center in Yapacaní; the other half were mothers and fathers whose child had been born at home. Interviewees for each group were purposively identified through collaboration with public health nurses and by going door-to-door in Yapacanís communities. In nearly all cases, each interviewee represented a different household. A semistructured question guide was used to elicit information. In order to avoid coming across as confrontational or judgmental, the interviewees were asked about why women in general do not go to the health services to give birth, rather than asking about personal decisions or experiences. This approach resulted in data regarding families' perceptions of the situation, rather than their personal experience. However, many responses were based on personal experience and this strategy may possibly have elicited more candid responses. Interviewees were also asked about their awareness of SUMI benefits and about their preferred birth setting.
The study included interviewees from three distinct areas and levels of access to health care : (1) urban Yapacaní, (2) rural Yapacaní with health services within $5 \mathrm{~km}$, and (3) rural Yapacaní with health services beyond $5 \mathrm{~km}$. This purposive sampling strategy ensures maximum variation in the sample and allows for highlighting of patterns and themes that emerge in spite of the variation (25). See Table 1 for a categorization of interviewees based on sex, location, and birthing status (home birth vs. institutional birth). Each individual was interviewed once for 20-40 minutes. For the most part, the interviews were conducted by the principal investigator; some were conducted by Bolivian colleagues from CEPAC. As needed, a translator assisted with Quechua-speaking interviewees. Interviews were recorded through handwritten notes that were annotated immediately following each interview to include contextual information and ensure accurate recall. The sample was largely homogenous in terms of occupation and low educational status. Interviewees were from 16-49 years of age. The results from these 62 semistructured interviews are presented in the Results section.

Eight open-ended interviews were conducted with local and regional key informants involved in health service provision and management (e.g., city officials, non-profit organization representatives, doctors, and regional government health administrators). Questions regarding the management, provision, and design of government reproductive health services elucidated political-economic and largescale social influences on access to health care for pregnant women. Each professional was formally interviewed once by the principal investigator. The interviews were tape-recorded and varied in length from 30-90 minutes. Additional informal conversations with these and other health service and non-profit employees were annotated and included in the analysis.

Relevant documents published by the MSD and other health-related institutions in Bolivia were used as references. These included descriptions of the Bolivian health care system (16), a SUMI implementation manual (26), tracking forms used by the health system for billing of services and epidemiological purposes (27), and a brochure from the Sociedad Boliviana de la Medicina Tradicional (Bolivian Society for Traditional Medicine, SOBOMETRA), which collaborates with the Santa Cruz departmental health administration (28). This information, along with the data from the key informant interviews and participant-observation provided the contextual information that helped frame the findings from the semistructured interviews. We return to these data in the Discussion section where we seek to explain what local women and men told us of their perceptions and expectations of local health care regarding pregnancy and birth.

Tape-recorded interviews were transcribed and all other interviews, notes, and annotations were transferred to word processing files. Data were analyzed using an inductive framework through the qualitative data analysis software ATLAS.ti (Scientific Software Development, Berlin, Germany) (29) by coding for key factors in relation to women's access to reproductive health care and quality of care in a decentralized health care system. This grounded-theory approach identifies themes that can be linked to existing theories and findings of related studies.

TABLE 1. Categorization of interviewees by location and birthing status ( $n=62$ ), Yapacaní, Bolivia, 2005

\begin{tabular}{|c|c|c|c|c|c|}
\hline \multicolumn{3}{|c|}{ Institutional births } & \multicolumn{3}{|c|}{ Home births } \\
\hline \multirow{2}{*}{$\begin{array}{l}\text { Area without } \\
\text { health service }\end{array}$} & \multicolumn{2}{|c|}{$\begin{array}{c}\text { Area with } \\
\text { health service }\end{array}$} & \multirow{2}{*}{$\begin{array}{l}\text { Area without } \\
\text { health service }\end{array}$} & \multicolumn{2}{|c|}{$\begin{array}{c}\text { Area with } \\
\text { health service }\end{array}$} \\
\hline & Urban & Rural & & Urban & Rural \\
\hline \multirow[t]{2}{*}{$\begin{array}{l}7 \text { female } \\
3 \text { male }\end{array}$} & $\begin{array}{l}6 \text { female } \\
4 \text { male }\end{array}$ & $\begin{array}{l}11 \text { female } \\
3 \text { male }\end{array}$ & $\begin{array}{l}8 \text { female } \\
3 \text { male }\end{array}$ & $\begin{array}{l}5 \text { female } \\
2 \text { male }\end{array}$ & $\begin{array}{l}7 \text { female } \\
3 \text { male }\end{array}$ \\
\hline & \multicolumn{2}{|c|}{ Total: 34} & \multicolumn{3}{|c|}{ Total: 28} \\
\hline
\end{tabular}




\section{RESULTS}

A large majority $(69.4 \%, n=43)$ of the 62 male and female participants of the semistructured interviews stated that they would, in general, prefer to have the birth take place at a health center rather than at home, while the remaining $30.6 \%$ $(n=19)$ would prefer a home birth. Given the $37 \%$ institutional birth rate recorded in Yapacaní in 2004, this finding suggests that many families who prefer to give birth in a health care setting are unable to do so. The study results address the reasons behind this inability to access care, as well as why some women prefer not to access care through the public health services.

Five principal reasons for the low rate of institutional births were identified among the semistructured interview data: first, fear of or embarrassment related to receiving care at a public health center (37\%); second, the perception that the quality of care at the center is poor $(22 \%)$; third, distance or other geographic challenges (21\%); fourth, financial constraints preventing arrival at or utilization of the health center (14\%); and fifth, the expectation of an "easy birth" (6\%). These results are considered within the "Three Delays" model developed by Barnes-Josiah et al. (30) during their work in Haiti, a country with a maternal mortality rate higher than that of Bolivia. This model provides a way to understand pregnancy-related mortality as a result of delays in (a) deciding to seek appropriate medical help for an obstetric emergency, (b) reaching an appropriate obstetric facility, and (c) receiving adequate care at the facility. It allows for analysis of the complex interplay between women's personal perceptions and decisions, the difficulties they experience in reaching an appropriate facility, and the quality of care received following arrival. The Three Delays model assumes that preventable maternal mortality occurs primarily because of inaccessibility of quality, culturally-appropriate reproductive health care services, and thus seeks to explain the multilevel factors that prohibit women from accessing these services.

Barnes-Josiah et al. (30) describe the first delay as the initial decision not to seek care. Results from the present study show that many factors influence a woman's initial decision not to seek care. First, many women are frightened or embarrassed to go to the health service, due to unfamiliar practices and their perception of the treatment they will receive. For example, one woman said, "In the hospital, everyone looks at us and they open our legs." Another said, "I am scared that they will scold me in the hospital because I've only gone to one prenatal check-up." Many interviewees stated that women are afraid of the doctor and that they are used to being attended to by a family member or midwife. Interviewees also explained that the quality of service in health centers causes fear because, as one woman stated, "The woman can die in the hospital." This fear and lack of confidence in the system can be linked to the quality of care in the health services setting, including attitudes of health personnel and resources available for providing adequate SUMI services (see Discussion).

Another reason that women decide not to seek institutional care at the time of birth is that they perceive the birthing process as easy. Some interviewees stated that women have an "easy birth," meaning that they have not experienced birth complications, and therefore, see no need to go to the health services. Several women made statements such as, "I don't go [to the health service] because I have had an easy birth ... if it were difficult, I would go." Thus, lack of biomedical understanding of the risks of obstetric emergency influences women's decision to remain at home to give birth. This view of birth as a natural, easy process is challenging for health care professionals to address because it is a fundamentally different conceptualization of childbirth.

Another reason women choose not to access health care services is unfamiliarity with SUMI. Almost half of all the interviewees were not familiar with the benefits of SUMI. Some expressed they had heard of SUMI, but that they thought it was "mentira" (a lie)-they didn't believe that the services are actually free of charge. The lack of information about SUMI and its apparent inability to live up to people's expectations is another important reason for the low rate of institutional births in Yapacaní.

A common assumption among health care professionals holds that women do not give birth at the health centers because their husbands do not permit it. However, more than $75 \%$ of the husbands responded that they prefer their wife to give birth at the health center, rather than at home. Thus, it became clear that, while a man may influence his wife's decision, the majority of the home births cannot be attributed to the husband's opinion.

The second set of factors noted in the "Three Delays" model (30) concerns actual access to services at the time of labor. Reaching an appropriate health care facility in the case of an obstetric emergency is an obvious challenge for residents in Yapacaní where no secondary- or tertiarylevel health service exists; the only option is to travel at least two hours by taxi to Santa Cruz. Even within Yapacaní, interviewees indicated difficulty arriving at a primary care facility due to economic and geographic factors. In most rural communities, buses pass through only a couple of times daily; people who are not within walking distance of a health service have limited transportation options at the time of birth. The distance to the nearest health service poses other logistical problems. One woman said, "There is no one to leave my children with and there is nowhere to stay in Yapacaní [when waiting to be admitted to the hospital]." Another pointed out that, "Many women give birth quickly. There is no time and you might give birth on the way."

Many interviewees articulated that because labor is unpredictable, planning transportation and child care in preparation for arriving at a health service is difficult. One woman said, "You don't know when the pain's going to hit you ... what can we do?" Thus, in addition to the basic problems of distance, rough roads, and infrequent transportation services, women face the inherent uncertainty of the birth process. It is clear that physical access to services is more than a matter of planning to access them. Access also requires sufficient infrastructure, such as transportation and childcare options.

Additionally, while economic barriers were to be alleviated through implementation of SUMI, interviewees pointed out that there are many other costs. For example, people felt that it was necessary to stay near the hospital for a few days after giving birth because, as one woman put it, "It's dangerous to leave [right away] due to the movement on the ride home." Transportation, costs of lodging, and lost days of work quickly add cost. Another major economic barrier is that SUMI is not 
in fact $100 \%$ free. Many interviewees told of paying for medicine in the hospital pharmacy and being charged for necessities such as cotton sheets, gas for the ambulance, laundry service, and food. Thus, in a context of widespread poverty, barriers to access extend beyond medical costs to include a range of factors that policy makers seem to have neglected to address when implementing SUMI.

The final set of delays identified by Barnes-Josiah et al. (30) revolves around receiving adequate care when a facility is reached. More than $50 \%$ of interviewees had complaints about the care provided, including issues surrounding the birth environment (i.e., who is allowed in room, position of woman during birth), health care personnel, health center resources, and timeliness/availability of medical attention. While some of the complaints were largely based on insufficient resources or technical capacity of the health services (ambulances, pharmaceuticals, sufficient beds, accommodations for family members, etc.), a more complicated and prevalent concern expressed was that the services are not culturally-appropriate and welcoming.

What do women and their husbands mean when they say "They [health personnel] don't provide good care?" First, doctors and nurses often do not speak the indigenous Quechua language of the many highland migrants in Yapacaní and are unfamiliar with or unwilling to administer services not within their Western biomedical training. For example, one woman said: "They leave us with pain, there are no remedies from the countryside [medicinal plants] that are hot and make us sweat so that the baby will be born." Interviewees were also concerned with unfamiliar medical practices, such as "tying down" women and using machines that "give more pain to the belly." One woman pointed out that when the baby is in a bad position, the doctor will operate; this, along with ultrasounds and urine analysis, deters many women from going to the health services. A few people felt that the hospital was a risky place to give birth and consequently many women prefer to stay home or see care from a paid midwife. They told stories of bad things that happened to women and children in the hospital and some spoke of the lack of training and poor bedside man- ners of the doctors and nurses. Other descriptions of poor care concerned the way that the doctors and nurses treat the women, typically without respect and thoroughness: "Not all doctors are the same, some are tiresome and they scold the women. They leave them screaming and they tell them 'suck it up now like you did with your husband.' " Another woman commented: "They don't attend quickly, only when they feel like it, and people can die in the hospital. The doctors leave the women in the stretchers alone... the nurses are around but they look at [the women] and don't do anything." In this context, one questions the assumption that it is in fact safer to give birth in the health service than at home.

All of the cultural, geographic, economic, and logistical factors identified in this study interact with each other, making the situation more complicated than the simple three-part taxonomy proposed by Barnes-Josiah et al. (30). For example, women's fears and reluctance to go to a health service often stem from perceived quality of care; distance and economics can pose problems because of the lack of resources available in health services (e.g., even if the health center has an ambulance, many times there is no phone or radio so that women cannot contact them for a ride); and an unperceived need for help from trained professionals (i.e., "easy birth") persists partly due to a lack of community outreach by the health centers explaining the benefits of biomedical services.

\section{DISCUSSION}

All of the factors identified within the "Three Delays" framework contribute to a situation in which not all Yapacaní women have access to quality maternal health care services at the time of birth and many women give birth at home. The proximal reasons articulated by women and men for home birth (i.e., fear or embarrassment, quality of care, geography, economics, and a perception of "easy birth") exist within the context of a host of structural factors that influence the experience of women and their partners at the time of birth. These large scale, contextual issues were explored in the open-ended interviews with key informants and in analysis of written documents. Understanding these issues is mandatory for making recommendations for improving health services access at the time of birth. This network of macrolevel political, economic, and social factors contributing to the lack of access to quality services is discussed below.

\section{Structural constraints}

The organization, financing, and management of the Bolivian national health system determine the framework in which SUMI is implemented and impact services at the local level. A key finding of this research was that it is difficult to ensure that MSD policy norms are followed when SUMI programs are put into practice. Health policy states that SUMI "expenditures are adapted to the uses, customs, languages, and dialects respecting identity, cultural bases, and a focus on gender" (28). Specifically, health workers are said to receive training on the provision of "humanized birth" services that respect Bolivian women's cultural preferences regarding birth position and ambiance. However, in Yapacaní, "humanized" births do not take place, midwives are not incorporated into the health system, and traditional remedies are not offered. Incorporating traditional birth attendants into the government health system and/or training health workers in traditional practices is an expensive and time-consuming task. Training is especially challenging given the large turnover in health care personnel and the need for extra equipment, such as proper chairs for women who prefer to give birth in a seated position. Additionally, as one administrator from the Santa Cruz health administration pointed out, there are not yet protocols for the use of traditional medicines within SUMI.

The failure to translate policy into practice is influenced by the financial environment of the Bolivian health system. According to the United Nations Children's Fund (31), only 3\% of Bolivia's national expenditure is spent on health care compared to an average of $6 \%$ for Latin American and the Caribbean countries and an average of $14 \%$ for industrialized countries. Also, it takes a significant effort on the part of the nation to ensure that money saved by debt relief under the 
Heavily Indebted Poor Countries initiative is redirected to improve the health of the poor (32). Bolivia's reproductive health care reforms are based on the primary health care model introduced through the Declaration of Alma Ata in 1978 (33). Primary health care emphasizes that universal care packages, such as SUMI, should be based on cost-effectiveness and the use of unpaid lay health workers who act as a referral system for emergency cases (34). However, previous studies have shown that the expectations placed on the lay health worker are often unreasonable due to limited time and resources (35).

It is within a context of scarcity that SUMI has been implemented. As a result, many interviewees were charged for basic supplies, such as bed sheets, laundry, and medicine, even though they were told that care would cost them nothing. Problems inherent in SUMI, such as a lack of funding for basic health center infrastructure (e.g., laundry services, ambulances, culturally appropriate birthing equipment), for extra staff to meet increasing demand, and for education and communication about SUMI, represent hidden costs that undermine confidence in the reproductive health services in Yapacaní. Additionally, SUMI legislation does not take into account the different economic climates found in Bolivia's municipalities; so, impoverished municipalities like Yapacaní do not have extra funds to improve the setting in which SUMI is delivered, and therefore, inequalities in access to and quality of care persist. One result of the shortfall in small municipalities such as Yapacaní is that health centers are not motivated to spend resources to promote SUMI; rather, scarce resources go toward infrastructure-related needs, such as electric bills, basic supplies, etc. These hidden costs impede implementation of SUMI at the local level, and must be addressed in any genuine effort to create comprehensive, quality maternal health services.

Not only is there a lack of funds for infrastructure, but allocating scarce SUMI resources efficiently and fairly to meet the demands of the population is also problematic. While corruption is difficult to document, key informants referenced general instances of corruption, such as the allocation of scarce medicines to friends and family members of the munic- ipal government, spending of resources allocated for SUMI for other items such as the mayor's salary, and robbing of money from hospitals.

\section{Political and administrative barriers}

The main proposed benefit of local community participation in health is the ability to plan and allocate resources according to local needs and priorities. However, discussions with key informants paint a picture of a fragmented health care system in which different levels of the hierarchy are not communicating and communities do not successfully articulate with the larger system. While decisions are decentralized, the resources themselves (including medicine, SUMI supplies, and personnel) remain vertically integrated. Additionally, the prioritization of local needs by the municipalities under the LPP is problematic for several reasons. First, municipalities often favor new soccer fields or plazas because these are more visible than improved health care infrastructure. Local community groups that comprise the "vigilance committee" and whose representative acts as the liaison between the community and the municipal government do not necessarily express the need for higher health care quality, although they do have a say in the budget allocations. Furthermore, not many people are aware of their right to participate under the LPP, such that they fail to express their concerns to the vigilance committee, and thus, feel powerless.

Communication among the different levels of the health system hierarchy (municipal, provincial, departmental, and national) is often problematic, causing delays in funding at the municipal level. The complex system of local documentation of care under SUMI causes reimbursement delays to local municipalities. Filling out paperwork to justify receipt of funds from the national government takes up an enormous amount of time and diverts time and energy from actually providing services. In visits to the central Yapacaní hospital, health workers from distant communities were often observed leaving their posts for the sole purpose of turning in monitoring sheets to qualify for eventual reimbursement for SUMI services. Without computers or even radios in the health services, keeping track of the services provided is a significant burden on health care workers. According to one key informant, because of the administrative challenges in a multitiered health system, the local health care administrative body (Dirección Local de la Salud) meetings are used to calculate debts and inventories rather than to prioritize local health needs. Also, local health authorities have been unable to get a response from the national level regarding possible revisions and complaints that they sent regarding SUMI legislation (e.g., incorporating funds for patient food and laundry).

The political power of the local governments over health personnel in a decentralized system limits what the health services can accomplish. Frequent changes in political parties mean that doctors, nurses, and administrators also change frequently, resulting in providers that are not necessarily qualified or motivated, and women who are more likely to receive inadequate attention and become frustrated. Politically-driven turnover is exacerbated by the lack of health personnel, especially in rural areas, and political strategies that aggravate the deficiency. Full-time salaried government health care positions are often divided so that two rural areas can be covered for the price of one. Doctors either end up working full days for half price because of the demands of the community, or if they work only the half-time for which they are paid, the community perceives it as poor quality of service. Until more salaried government health care positions are provided for rural doctors, the lack of adequately paid workers in rural areas is a serious barrier to improving the quality of services.

Another problematic policy within the MSD is a law stating that full-time health workers are only required to work six hour days in publicly-funded clinics. The purpose of the law is to give low-paid governmental health personnel time for private practice, to continue their education, and to do public health prevention in the community. However, one administrator suggested that the reality is that health personnel rarely use the extra two hours a day for anything but free time. Personnel deficiency is also aggravated by the high rates of migration into Yapacaní. Homedes and Ugalde (36) provide a more 
in-depth discussion of the "unprepared managers and unhappy workers" phenomenon in Latin America's neoliberal health sector reforms.

Thus, the decentralized health care in Yapacaní is wrought with political influence, lack of resources, limited community participation, and communication challenges all the way up the hierarchical administrative ladder. Implementation of SUMI, a law designed to function within the ideal decentralized system, is negatively influenced by these structural obstacles, ones that inhibit the successful realization of good quality, efficient, reproductive health care at the local level.

\section{Substandard patient services}

A large component of the perceived poor quality of Yapacaní's health services is the unwelcoming and degrading way that the health care workers treat the patients. Although SUMI advertisements, created at the national level and distributed in rural communities, warmly encourage women to visit culturally-sensitive health services, upon arrival women are often met with indifference and hostility. In this context, it should be no surprise that women are afraid and embarrassed to give birth in a health center. It is possible that many health care providers, due to frequent turnover and deficient cultural sensitivity training, are unaware of the SUMI edicts that stress conforming services to the cultural needs of pregnant women. Women themselves pointed out that many doctors are inexperienced, knowing more about how to bill the patient than how to attend to their needs. Even when health personnel are familiar with SUMI's norms, they often lack re- sources and time to provide adequate service. Also, the lack of permanent physicians in rural health centers means that minimally-trained and unlicensed health workers often attend to births.

Another reason for substandard performance among the health workers is an unwillingness to comply with SUMI standards. Social class and ethnic conflicts may influence predominantly camba (Santa Cruz native) health care professionals' treatment of colla (indigenous) migrant women who generally have darker skin, are poor, and often have limited Spanish language skills. Several interviewees mentioned that one of the reasons colla women are treated poorly in the health services is because they are "from the countryside," meaning they are of a different culture, ethnicity, and class. Justice (35) documented similar conflicts in Nepal where the health center staff had not received appropriate training to sensitize them to rural working conditions. Additionally, despite a formal discourse to the contrary, institutional maternalchild health policies and services at the primary-care level in developing countries, including Bolivia, continue to be largely driven by an ideology that strives for modernization, sophisticated technology, and the medicalization of pregnancy and childbirth (37).

Medicalization of childbirth is, "The process whereby the medical establishment ... incorporates birth in the category of disease and requires that a medical professional oversee the birth process and determine treatment" (38). In this scenario, physicians gain the sole authority for providing reproductive health care and tend to be blind to the cultural traditions of the indigenous population, as described by Jordan (39). In an attempt to expand the limits of a medicalized reproductive health care system and incorporate local birth preferences, the Santa Cruz health administration is beginning to coordinate with SOBOMETRA. This effort will begin training natural medicine practitioners and traditional birth attendants about SUMI protocols so that they can start caring for pregnant women in the government health centers. A representative from this organization argues that the integration is often one-sided, in the sense that it often feels as though traditional medicine is being allowed into the framework of SUMI only if its practitioners are properly trained by Western medical standards, rather than having a two-way process where government health workers are also trained in traditional medicine practices. Thus, the current situation represents a stage of transition in which the government administration must work to successfully implement a culturallyappropriate system that integrates ethnomedical and biomedical components. Until then, women's unease with biomedicine will continue to manifest itself in their embarrassment, fright, and unwillingness to go to health centers at the time of birth.

In conclusion, assuring that all women have access to and utilize SUMI resources at the time of birth plays an important role in efforts to decrease maternal mortality rates and internal disparities within Bolivia. In response to the structural and social issues discussed, resources must be specifically targeted by the MSD and the international community to ensure that SUMI services will successfully instill confidence in Bolivian women and facilitate their overcoming the cultural, geographic, economic, and logistical barriers to accessing "free" services.

\section{REFERENCES}

1. World Health Organization. World health report 2005-make every mother and child count. Geneva: WHO; 2005

2. United Nations Population Fund. Country profiles [Internet site]. Available from: http:// www.unfpa.org/latinamerica/. Accessed 23 September 2006.

3. Stephenson R, Baschieri A, Clements S, Hennink M, Madise N. Contextual influences on the use of health facilities for childbirth in Africa. Am J Public Health. 2006:96(1): 84-93.
4. Berry NS. Kaqchikel midwives, home births, and emergency obstetric referrals in Guatemala: contextualizing the choice to stay home. Soc Sci Med. 2006:62(8):1958-69.

5. Mavalankar D, Rosenfield A. Maternal mortality in resource-poor settings: policy barriers to care. Am J Public Health. 2005:95(2):200-3.

6. Kyomuhendo G. Use of rural maternity services in Uganda: impact of women's status, traditional beliefs and limited resources. Reprod Health Matters. 2003:11(21):16-26.
7. Stephenson R, Tsui A. Contextual influences on reproductive wellness in northern India. Am J Public Health. 2003:93(11):1820-29.

8. Paul B, Rumsey D. Utilization of health facilities and trained birth attendants for childbirth in rural Bangladesh: an empirical study. Soc Sci Med. 2002:54:1755-65.

9. Griffiths P, Stephenson R. Understanding users' perspectives of barriers to maternal health care use in Maharashtra, India. J Biosoc Sci. 2001:33:339-59. 
10. Amooti-Kaguna B, Nuwaha F. Factors influencing choice of delivery sites in Rakai district of Uganda. Soc Sci Med. 2000:50:203-13.

11. Midhet F, Becker S, Berendes H. Contextual determinants of maternal mortality in rural Pakistan. Soc Sci Med. 1998:46(12):1587-98.

12. Thaddeus S, Maine D. Too far to walk: maternal mortality in context. Soc Sci Med. 1994: 38(8):1091-110.

13. Instituto Nacional de Estadística de Bolivia. Proyecciones de la población por municipios [Internet site]. Available from: http://www. ine.gov.bo/. Accessed 27 September 2006.

14. United Nations Development Programme. Human development reports: Bolivia country sheet [Internet site]. Available from: http:// hdr.undp.org/statistics/data/countries.cfm? c=BOL. Accessed 26 September 2006.

15. Pan American Health Organization. Investment in health: social and economic returns, scientific and technical publication no. 582. Washington D.C.: PAHO; 2003

16. Ministerio de Salud y Deportes. Política nacional de salud, serie: documentos de políticas. Bolivia: MSD; 2004.

17. Pan American Health Organization. Health services system profile: Bolivia [Internet site]. Available from: http://www.lachsr.org/ documents/healthsystemprofileofboliviaEN.pdf. Accessed 26 September 2006.

18. Janes CR, Chuluundorj O. Free markets and dead mothers: the social ecology of maternal mortality in post-socialist Mongolia. Med Anthropol Q. 2004:18(2):230-57.
19. McElroy A, Townsend P. Medical anthropology in ecological perspective. 4th ed. Boulder, CO: Westview Press; 2004.

20. AbouZahr C, Wardlaw T, Stanton C, Hill K. Maternal mortality. Bull World Health Organ. 1996:49(2):77-87.

21. Patton MQ. Qualitative research and evaluation methods. 3rd ed. Thousand Oaks, CA: Sage Publications; 2002.

22. Ezechi OC, Fasubaa OB, Obiesie LO, Kalu BKE, Loto OM, Dubub VI, et al. Delivery outside hospital after antenatal care: prevalence and its predictors. J Obstet Gynaecol. 2004: 24(7):745-9.

23. Boender CL. Choice of birth setting among urban Bolivian women [MA thesis]. Denver (CO): University of Colorado at Denver; 2000.

24. Bhatia JC, Cleland J. Determinants of maternal care in south India. Health Transition Review. 1995:2:127-42.

25. Bernard HR. Social research methods: qualitative and quantitative approaches. Thousand Oaks: Sage Publications; 2000.

26. Ministerio de Salud y Deportes. Módulo de inducción. Bolivia: MSD; 2002.

27. Ministerio de Salud y Deportes. Formulario de monitoreo de gastos. Bolivia: MSD; 2002.

28. Sociedad Boliviana de la Medicina Tradicional. Folleto. Bolivia: SOBOMETRA; 2005.

29. Muhr, T. ATLAS.ti. Berlin: Scientific Software Development; 2000.

30. Barnes-Josiah D, Myntti C, Augustin A. The "three delays" as a framework for examining maternal mortality in Haiti. Soc Sci Med. 1998: 46(8):981-993.
31. United Nations Children's Fund. State of the world's children report (2001) [Internet site] Available from: http://unicef.org/sowc01/ tables/\#. Accessed 15 July 2006

32. International Monetary Fund. Fact sheet: debt relief under the heavily indebted poor countries (HIPC) initiative [Internet site]. Available from: http://www.imf.org/external/np/exr/ facts/hipc.htm. Accessed 22 September 2006.

33. Barton WL. Alma-Ata: signpost to a new health era. World Health. 1979:July:10-15.

34. Janes CR. Going global in century XXI: medical anthropology and the new primary health care. Hum Org. 2004:63(4):457-71

35. Justice J. Policies, plans, and people. Berkeley, CA: University of California Press; 1986.

36. Homedes N, Ugalde A. Neoliberal health sector reforms in Latin America: unprepared managers and unhappy workers. Rev Panam Salud Publica. 2005:17(3):202-9.

37. Sesia PM. Women come here on their own when they need to: prenatal care, authoritative knowledge, and maternal health in Oaxaca. Med Anthropol Q. 1996:10(2):121-40.

38. Van Hollen C. Birth on the threshold. Berkeley, CA: University of California Press; 2003.

39. Jordan B. Birth in four cultures. 4th ed. Long Grove, IL: Waveland Press, Inc; 1993.

Manuscript received on 6 July 2007. Revised version accepted for publication on 14 March 2008.

RESUMEN Objetivos. Se investigó la baja tasa de partos en hospitales y centros de salud de Yapacaní, Bolivia, que persiste a pesar del programa nacional de seguro materno-infantil diseñado para garantizar el acceso equitativo a centros gratuitos de atención sanitaria

Barreras al parto hospitalario: ¿por qué muchas bolivianas dan a luz en casa? para embarazadas. El objetivo de este estudio fue identificar los factores que a diversos niveles inhiben el acceso a centros públicos de salud para partos y su utilización.

Métodos. Se emplearon métodos cualitativos, entre ellos la observación participante, entrevistas semiestructuradas a 62 miembros de la comunidad y entrevistas a informantes clave con ocho expertos regionales. Los datos se codificaron y analizaron mediante el enfoque de teoría fundamentada.

Resultados. A partir de las entrevistas semiestructuradas se identificaron cinco razones para la baja tasa de partos institucionales y se establecieron sus frecuencias: 1) miedo o vergüenza a atenderse en un centro público de salud $(37 \%) ; 2)$ baja calidad de la atención en los centros de salud $(22 \%)$; 3 ) lejanía u otras barreras geográficas que impedían llegar oportunamente a los centros de salud $(21 \%) ; 4)$ limitaciones económicas que impedían hacer el viaje o utilizar los servicios (14\%); y 5) la percepción de que la atención sanitaria no era necesaria debido a la experiencia de "partos fáciles" (6\%).

Conclusiones. Las razones de la baja tasa de partos observada en los centros públicos de salud estudiados se insertan en un contexto de escasos recursos, políticas deficientes y diferencias culturales que influyen en la experiencia de las mujeres y sus parejas en el momento del parto. Para mejorar el acceso a una atención sanitaria de calidad para todas las mujeres bolivianas en el momento del parto se deben tomar en cuenta estos problemas generalizados y contextuales. A nivel nacional, los recursos deben asignarse con cuidado para garantizar que los servicios gubernamentales logren inspirar confianza a las mujeres bolivianas y faciliten que puedan vencer las barreras culturales, geográficas, económicas y logísticas que obstaculizan su acceso a servicios "gratuitos".

Palabras clave Parto domiciliario, centros independientes de asistencia al embarazo y al parto, parto humanizado, política de salud, mortalidad materna, Bolivia. 